\title{
It doesn't make sense, but we do: framing disease in an online metastatic breast cancer support community
}

\author{
Ariane B. Anderson \\ Department of Communication, University of South Florida, Tampa, Florida, USA
}

\begin{abstract}
Using Weick's sensemaking as a conceptual framework to investigate online discussions between members of a Facebook group of metastatic breast cancer patients, and using thematic analysis to examine textual threads between group members, this research examines participants' framing of cancer survivorship. Participants in peer-to-peer disease support groups, which are not led by medical experts, communicate differently among themselves in order to cope with chronic and terminal illness. Perceptions of survivorship of late stage patients versus early stage patients differ for a variety of reasons, with late stage patients understanding their illness trajectory more often as chronic and declining. This analysis identified three properties of sensemaking used by members to manage their disease: identity, retrospective, and enactment. Results indicate that peer-to-peer online support group communication engenders distinct framing logics that members draw upon for group support as they manage a chronic and terminal disease.
\end{abstract}

The boundaries between narrative and scientific knowledge are permeable, and both forms of reasoning arrive in packages that are inseparable aspects of the same thing - both frame and picture Barbara Czarniawska (1998) ${ }^{1}$

\section{Introduction}

The original definition of survivor describes the cancer patient as experiencing neither death nor cure, but rather, struggling through inexact yet predictable stages of a deadly disease.$^{1-3}$ Meanings of breast cancer survivorship have gone

Correspondence: Ariane B. Anderson, Department of Communication, University of South Florida, 4202 E Fowler Ave, CIS 1040, Tampa, Florida, USA

E-mail: abanders@mail.usf.edu

Key words: Metastatic breast cancer; Sensemaking; Online; Identity; Survivor.

Conflict of interest: the author declares no potential conflict of interest.

Funding: none.

Received for publication: 22 August 2017.

Revision received: 11 July 2019.

Accepted for publication: 11 July 2019.

This work is licensed under a Creative Commons Attribution NonCommercial 4.0 License (CC BY-NC 4.0).

${ }^{\circ}$ Copyright: the Author(s), 2019

Licensee PAGEPress, Italy

Qualitative Research in Medicine \& Healthcare 2019; 3:68-75

doi:10.4081/qrmh.2019.7007 through a stark metamorphosis in the last 50 years, ranging from a once private and stigmatized disease to contemporary disease discourse which evokes the cultural metaphors of fighting, war, heroism and virtue. ${ }^{4}$ Such metaphors have fueled enormous public support of the breast cancer survivor identity. Images of predominantly white, physically fit, upper middle class, heterosexual females who triumph over the disease by sheer optimism and willpower have overshadowed the stark reality that despite billions of dollars spent for Breast Cancer Awareness marketing and initiatives for races for the cure and early detection, death rates for breast cancer have remained relatively static. ${ }^{5}$ Today, as in 2005,1 in 8 women in the U.S. will be diagnosed with breast cancer, and 1 in 6 of those diagnosed will die from the disease. ${ }^{5,6}$ The differences between representations of breast cancer awareness and survival statistics leave some breast cancer patients struggling to reconcile their own personal experiences with dominant images of survivorship. For instance, metastatic cancer patients consider current definitions alienating because of their own fears of the disease progressing in the context of the positive entailments of metaphors of fighting and beating the disease. ${ }^{7,8}$ One response to isolating messages on the part of metastatic breast cancer (MBC) patients has been that of seeking out patients who have been diagnosed as being at a similar stage in the progression of their cancer to discuss their shared concerns.

Increasingly, $\mathrm{MBC}$ patients are turning to online, peerled, cancer patient support groups as opposed to traditional online message boards or forums led by medical experts as places to connect with like-minded others. Most MBC patients have unique physiological and psychosocial needs and experience the isolating effects of diagnosis and treatments on some level. ${ }^{9}$ This article examines one such online peer-to-peer MBC support group - The Living Room, TLR - to identify ways members' shared discourse may represent organizational sensemaking in the 
service of deriving meaning from an often terminal disease experience. In the section that follows, I will review existing literature surrounding online disease support groups and sensemaking and justify the rationale for examining $\mathrm{MBC}$ patients' understandings of their disease.

\section{Literature review}

Preece defines online support communities as any virtual social space where people come together to get and give information or support, to learn, or to find company. ${ }^{10}$ In online spaces cancer patients seek to gather information, feel connected socially, and increase their personal and collective sense making of their disease. ${ }^{11}$ Moreover, the ubiquity and ease of access of online communication has enabled patients to seek informational and emotional support from countless blogs and social media support groups such as Facebook, Twitter, and Reddit. ${ }^{12}$

Online support groups for breast cancer patients began to flourish in the mid 1990s when disease focused groups began to form as places for information exchange and mutual support. ${ }^{13}$ Researchers at that time were looking at how groups form and were mainly concerned with information control and how such information seeking would impact patient-provider understanding. ${ }^{13}$ Sillence researched participants' exchange of peer advice in an online breast cancer support group for ways that advice-giving impacts patient decision-making and shapes groups as resources for decision making. ${ }^{11} \mathrm{Oh}$ and Lee examined how the exchange of computer mediated support influences patients' sense of empowerment and its effects on patient-provider communication..$^{14}$ While much of the research on communication in online health-related support groups has focused on participation, means of support, and health outcomes, less has examined online groups as spaces for alternative disease discourses - or socially desirable stories and outcomes. ${ }^{12,15,16}$ For instance, MBC participants of online support groups engage in freer expression between similar members because online contexts can function as liberating realms which allow for the telling of less socially desirable stories. ${ }^{17,18}$

\section{Benefits of online support group participation}

The anonymity permitted by online communication allows for participants in online support groups to discuss difficult topics that involve intense emotions regarding declining health and end of life issues. ${ }^{19}$ Such online disclosures can contribute to patients' greater sense of coping and overall wellbeing. ${ }^{19,20}$ Moreover, in Vilhauer's study of a mixed-stage groups, MBC members described feeling more support from each other, because of seeing each other living well despite $M B C$ which in turn made them feel more hopeful. ${ }^{21}$ Patients describing their illnesses and impairments to each other in online support settings consists of an ongoing negotiation and renegotiation of their identity as patients and contributes to how they continuously frame their sense of self in relationship to others. ${ }^{22}$

\section{Framing reality/sensemaking}

The practice of framing experiences in organizational life to collaboratively derive meaning from them is a process conceptualized by Karl Weick in terms of sensemaking. ${ }^{23}$ It should be noted that TLR is a bounded (private, invitation only) community of MBC members. While not strictly an organization, which is a essentially a grouping or system that has hierarchal structure and pragmatic goals, TLR exists as a distinct, peer centered, group of members who have common characteristics and are motivated by a mission statement.

In turn, Weick's sensemaking is connected to Schutz's concept of finite provinces of meaning by which Schutz argued that it is the meaning of our experience and not the ontological structure of the objects which constitute reality. ${ }^{24}$ In other words, the commonsense world is really a sociocultural world wherein the consensus of reality is reached by the perceptions of participants using the affordances of language and symbols. Metaphors are powerful examples of this, as they are sites for authoring of experience. As Sontag argues in her classic work on Illness as Metaphor, ${ }^{4}$ the commonality of war and battle metaphors has meant that cancer is entangled in a social context of the entailments of winning and losing. We see war metaphors at work in cancer sensemaking in bio-medical discourse, in the narratives of patients and physicians alike, and in ways that are highly consequential to our understanding of the moral standing of the characters as well as the resolution of these narratives.

The basic idea of sensemaking is that reality is an ongoing accomplishment that emerges from efforts to create order and make retrospective sense of what occurs. As Weick maintains, sensemaking is no more than what the words imply, it literally is making something sensible. $^{2}$

Landqvist maintains that online illness support groups act as epistemic arenas, where chronically and terminally ill patients understand, negotiate, and renegotiate their disease identities. ${ }^{25}$ Likewise, this study examines how an online support group of MBC patients create, sustain, and repair their own order. Furthermore, this study of health-related online support groups fills an existing gap in health communication research in the areas of survivorship and organizational/group communication. I propose the use of Weick's seven characteristics of sensemaking that distinguish it from other explanatory methods of organizational sensemaking: i) grounded in identity construction; ii) retrospective; iii) enactive of sensible environments; iv) social; v) ongoing; vi) focused on and by extracted cues; vii) driven by plausibility rather than accuracy. ${ }^{2}$

These interrelated properties help identify not only what kinds of sensemaking is at play, but also how it is working and where it might fail. I applied them to the analysis of textual threads posted by members of TLR and online MBC support group. 


\section{Research context}

This study is guided by the following question: In what ways do the members of TLR, understand and frame their disease?

To address it, I collected textual exchanges between members of TLR found in the online platform of Facebook. TLR is an invitation-only group of MBC patients and was formed as a sister group of Booby Buddies (stage 0-3 breast cancer). The Facebook page for TLR reads, This is a private discussion group for 'Booby Buddies' with chronic breast cancer. Other women who are in the group are committed to praying for these women and their needs. Any woman who has MBC can join, but, for the purposes of protection of privacy and to enable more candid communication, prospective members, many of whom formally were 'Booby Buddies', must directly contact the founder and director, Jan James, to join. The membership count during the time of data collection was, TLR, stage $\mathrm{IV}=166$; Boobie Buddies, stage 0-3=866.

TLR was created in response to former members of Boobie Buddies who had new or subsequent diagnoses of $\mathrm{MBC}$ and who felt that much of the discussion found on the Booby Buddies forum did not reflect the challenges and concerns that MBC patients were experiencing. For instance, in Boobie Buddies, discussions centered around questions and answers regarding newly diagnosed or earlier stages of cancer diagnosis, the trauma of hair loss, breast reconstruction, as well as participants' celebratory announcements of completion of treatment or remission status. Members with $\mathrm{MBC}$ were typically experiencing very different events regarding their own treatment and prognosis. For example, many of the impairments brought on by the disease, together with treatment side effects for stage IV cancer patients can be harsher, more uncertain, and can go in in perpetuity. Members with MBC often cannot or do not want to undergo breast reconstructive surgery, and very few of the members of TLR can look forward to remission status.

\section{Materials and Methods}

\section{Data}

In order to analyze the data, I chose a systematic purposeful sampling. ${ }^{26}$ The criterion for each post was a minimum of two participants. The average post consisted of one thread and had 2-8 participants. An approximate of 207 posts by 57 members was accessed over a six-month period in 2017. Participants represented diverse ages, length of survivorship, economic class, religious beliefs, sexualities, and race.

\section{Analysis}

I analyzed the threads by way of qualitative content analysis, a method of analyzing written, verbal or visual communication messages. ${ }^{27}$ Elo and Kyngäs go on to state that through such analysis, it is possible to distil words into fewer content-related categories and make replicable and valid inferences from the data to their context. According to this procedure, I analyzed members' textual threads to determine if any categories existed for the purpose of examining the themes through the lens of Weick's properties of sensemaking. ${ }^{2}$

I compared participants' views contained in each of their short exchanges with each other and by taking initial analytic notes and memos, forms in the data began to take shape. I determined themes first, by open coding (where initial codes were provisional and grounded in the data) and next by axial coding (where synthesis and connections between words occurs), and finally by selective coding, where I determined broader themes.

I compared the content of participants' exchanges with each other and by taking initial analytic notes and memos, forms in the data began to take shape. Three dominant properties of sensemaking were identified: grounded in identity construction, retrospective and enactive of sensible environments. The following analysis consists of members' textual threads as examined through the lens of Weick's sensemaking in organizations.

\section{Results}

\section{Making sense of illness}

\section{Grounded in identity construction}

TLR, as a virtual community, is a private group consisting of patients who have had biographical disruptions caused by their disease diagnoses. ${ }^{28}$ Cancer is the $i t$ that is foundational to the dialogic events that occur in TLR. The direction between causality and events through which individuals think about themselves is contingent upon what one thinks it is and how it defines the self. In this multi-directional relationship of the definition of events and self within the setting of a late-stage disease community, members find themselves adapting to their own need for what Erez and Earley define as i) a need for a positive cognitive and affective state about the self; ii) motivation to see the self as efficacious and competent; and iii) the need for self-consistency - to experience coherence and continuity. ${ }^{29}$

The need for maintaining a consistent narrative of self is exemplified when new members are welcomed to the group. Linda (who is introduced by Tracy, one of the founding members) proceeds to describe her history of cancer and treatments and her preparation for participation in a drug trial, where an unexpected turn of events occurs with her subsequent return to chemo. Many members respond with Welcome, love and prayers, followed by emojis. These exchanges exemplify cues taken from the conduct of others where members are both shaping and reacting to this interactional environment. The continuation of a thread of short and similar greetings by the 
members clarifies and confirms group identity. This clarifying, confirming transaction is what Ring and Van de Ven refer to as an organization projecting itself onto its environment. ${ }^{30} \mathrm{An}$ immediate consensus of organizational identity is enacted, as each new member is welcomed, lengthy formalities are dispensed of, and issues of impairment are addressed.

Later in the thread, Darlene gives a more lengthy reply: so sorry! Sounds similar to my story. Mine came back in my spine and lungs, was eating away at the vertebrae. I'm on a great treatment plan that's working, praying they find the right one for you! Here, Darlene unhesitatingly identifies with Linda's diagnosis and condition as their notions of self are validated through articulations of knowledge of their bodies. Darlene's identification and validation reinforces a sense of coherence about the self in the midst of uncertain events and available treatments. The exchange shows the crucial ways in which sensemaking influences the approach that peers take when they begin initial processes of transacting with others. ${ }^{2}$ Members' sense of belonging is accomplished by transactional agreements of what is and is not talked about.

In the same thread, a need for and collaboration of selfefficacy is demonstrated when Bernadette posts that her chemo treatment of two years is causing a scarring of her lungs and that steroids are causing untenable side effects:

Bernadette: So it's like, breathe and take a chance or continue until I would be on oxygen. I just ask for prayer that the right decisions are made. And by the way...ONLY $1 \%$ of the people this happens to. Ellen: I feel ya. I seem to get the 1\% side effects too Gemzar did it to my lungs: I said no to the steroids. I coughed for 4 months and couldn't complete a sentence without wheezing.

Bernadette: I was afraid to not do the steroids. I couldn't even walk up the stairs I had no air. My breathing test should have been around 80 and I was 38. It was horrible.

Ellen: It sucks so bad that the drugs keeping us alive can make us so feel horrible. Ugh.

Ellen and Bernadette are being both proactive and reactive in their exchange as they simultaneously shape and react in this give and take, which Weick characterizes as reciprocal influence. ${ }^{2}$ In settings where mutability of the self is especially fluctuating, texts of the self are informed by texts of the other and environment. Members facilitate a coherence and consistency as they make sense of what is going on around them based on the implications on the self. To illustrate, rather than turning the negative side-effects of cancer treatments into something positive, as is common, especially among healthy people and earlier stage breast cancer patients, MBC peers do not attempt to explain the pain away or offer advice or solutions. Rather, they lend support in the form of empathetic comments and stories. The joint creation of members' perceptions and meaning act as forms of self-actualization as each influences the other's identity.

\section{Restrospective sensemaking}

Ethnomethodologists see sensemaking as an artifact of post diction, observation, and explanation. ${ }^{31}$ If people can know what they are seeing and doing only after the event or doing has passed, then, as Winokur says, reality is in the past and our intellectualizations of moments take place post-visualization. ${ }^{32}$ If our perceptions are indeed short-term memory work, then meaning making is derived from already-elapsed experiences, apprehended, and brought into relief based on our attention to marked out moments. ${ }^{25}$ In other words, what we pay attention to is contingent on stimulus, action, and context: all of which are subjectively selected and in actuality hindsight based on our sensory and motor skills. ${ }^{33}$ Many possible meanings are all going on at once which have to be synthesized by the perceiver. Individual and organizational values help perceivers sort out what to attend to. Accordingly, in discussions among metastatic cancer patients, one often finds an inclination to return to normalcy. Clinicians and patients commonly refer to a new normal as adapting to the ever-changing events of living with a chronic or acute disease. Participants' negotiation to achieve a sense of normalcy is unique in that acutely/terminally ill people are conscious that theirs is not a normal experience and that the future is uncertain. Therefore, the language used to affirm each other's experience operates to achieve a form of homeostasis.

A post in which Shelby, a prominent member, describes a recent encounter in her oncologist's office illustrates retrospective sensemaking at work:

Shelby: So this happened and I have had it on my mind. Ten days ago while I was at the clinic getting fluids, I sat by in my usual area. A new gal was a few seats away and looking ever so ill. The thought crossed my mind to introduce myself and to wish her well, I didn't. A few moments later her nurse is trying to get her to wake up by calling her name. Before I knew it we were all moved to the other side of the room and dozens of hospital help came running. A temporary screen was put up as they worked on her. The nurses were outstanding checking on all of us. They worked on her for an hour as her family began to arrive. Her name was --. It just brought the reality of my situation too close. Always say Hi.

Teresa: What a sad story. I will surely make it a point to say hi to all when I go for chemo treatment. Laura: Wow. What an experience. Life has a way of throwing reality at us in a brutal way sometimes. Shelby's phrase, Always say $H i$, acknowledges that the future is not guaranteed to this immediate population of patients or by association, to TLR. The phrase captures the idea that existing in a state of uncertainty is a baseline 
of normalcy for the metastatic patient. Thus, the practice of cultivating and possessing an awareness that the next person to die could be you or someone close to you is another, more profound new normal. A collective designation of meaning is being derived from a particular kind of attention given to this event and is shaped by members responses to Shelby's story.

The expression Always say $\mathrm{Hi}$ also acts as the stimulus to which Laura's response defines or shapes meaning. In so doing, Laura's selective attention frames this event as one that is particularly harsh for metastatic cancer patients to witness. Meanwhile, others who have witnessed the event, may have another perspective, i.e. the nurses as emergency responders, non-patients as curious onlookers, etc. In each individual case, the retrospection that occurs is created through the kinds of meaning that are attached to the event. Because of their shared reality, for TLR, Shelby's phrase provides a more urgent sense of immediacy, an intention toward, a necessary face-to-face communication that transcends the instrumental of everyday communication in clinical settings. Ella ends the thread by responding: That would be so hard to watch. After my little reaction, I have tremendous respect for the nurses and all the medical team. Yes definitely will say Hi to those next to me.

Ella verifies members' retrospective sensemaking by connecting her own responses to members creating meaning out of a brutal scene and to make visible the enactment of organizational identity in the future.

\section{Enactment of sensible environments}

Enactment, according to Weick, is a making of that which is sensed. People use interpretation to explain things that are already there, sensemaking is used to explain how things got there to begin with; thus, action enables people to see what they think. ${ }^{34}$ Action, individual and collective, is not separate from the construction of the environment in which an event occurs, rather, action and environment co-create each other. Action contributes to the overall definition of what is understood to have taken place. Because activity creates stimuli, action also creates both the constraints and opportunities that emerge from environments - all as a result of the interplay of subject and object.

In TLR enactment occurs most typically in response to health status updates, which are at the heart of the group's purpose. Members routinely post changes in treatment regimens, discovery of new lesions and tumors, entrance to hospice care, or less often, news of remission. In response to such reports, participants offer textual support in the form of words and graphics; equally common is the offer of non-sectarian prayers. Leanna announces in large, bolded text:

Leanna: 4 brain tumors. Explains a lot. Won't tell

kids until we have a plan-feeling broken.

In this space of bad news, participants may imagine that they could have easily written the post about themselves. In response, members enact the meaning of this diagnosis through supportive language, emojis, and banners.

There are few comments appearing to overtly prescribe actions or contain common understandings of how breast cancer patients are expected to think positive or to fight. Instead, responses range from:

So sorry; Sorry this is so hard; My thoughts are with you!!!, to Love you sister, God has a perfect plan for you and your precious family, Xoxox; You and your family are in our prayers; You may not find the words, because there are no good words. But you will find the love. And the embrace. And the way to tell your kids. That is my prayer; and finally, I am praying there's an option or availability or a chance to do a new drug trial drug something to help you I'm so sorry.

Respondents seem to be trying to refrain from saying things that will attempt to fix the problem; rather, they are creating new ways to think about the diagnosis without diminishing its impact on Leanna. The way that both Leanna and members are discussing this news demonstrates the relatedness of action and environment. The stimulus of the situation (news of the diagnosis) facilitates the actions (support), thus both producing new situations which cause new activities - all intersubjectively produced. Members' enactment of the environment changes the way they are thinking about the post $a s$ they are acting. ${ }^{35}$

\section{We are all just walking each other home}

Metaphorical meanings often emerge in response to loss of control and traumatic events. These meanings contain tacitly accepted organizational scripts. A co-creation of what has just been sensed is illustrated by a member's spouse reporting that member's transition in to hospice care. Shelby, who regularly posts things such as Always say $\mathrm{Hi}$, has entered hospice. Her husband says:

Jack: Ladies....This is Shelby's husband Jack. Shelby took a turn for the worse last nite and The Hospice nurses are telling me she doesn't have much time left. I wanted to tell you all thanks from the bottom of our hearts for being apart of this journey. You all meant so much to her and I will continue to pray for you all and ask for Gods grace for each and everyone of you on your own journeys.

XXX: prayers will be flooding your way throughout these difficult days. Please keep us posted on our precious Shelby's progress to her heavenly home. Our lives will never be the same for having known her. Love and prayers, friend. May all of you feel the Lord's presence and comfort.

XXX: So sorry, so sad...

XXX: I'm so very sorry to hear this news. Breaking my heart. Thank you for letting us know Jack Prayers for you \& your family [Two red heart emojis, two prayer hands emojis]. 
XXX: Aw, I hate that. Prayers, sweet and kind woman.

XXX: Jack, I'm so sorry. Shelby is so sweet. I'll be praying for her and your family.

XXX: Jack, thinking of you. Shelby has been a pillar of strength, especially for us newly diagnosed. XXX: I'm beside myself. I am so sad, I thought the world of her. I was hoping to meet her sometime. I will bid her farewell for now, but we will meet again, I know. Prays for the family.

XXX: Jack, prayers for comfort and peace for you and your entire family. Shelby, you are such a sweet nice woman! This really breaks my heart. The world is losing one of its brightest lights.

XXX: Sending prayers and hugs to everyone. May you all find some comfort during this most difficult time [A red heart emoji].

XXX: A friend of mine often uses an expression that I love...prayers are flying up for you! [A red heart emoji].

Amy: Just in the last few weeks Shelby used the phrase....we are all just walking each other home.

Thanks for being part of my walk Shelby. Xxxooo.

Typically, a greater number of members respond to these kinds of notifications; more than 50 responses follow - the majority expressing sadness and promises of prayers.

Of note is a post by Amy who says, Just in the last few weeks Shelby used the phrase......we are all just walking each other home. Thanks for being part of my walk Shelby. Xxxooo. Amy also posts a photograph of a cup with the inscribed words, We are all just walking each other home. The image captures a clearly active making of that which is sensed by the others. For these late stage patients, the symbols denote a virtual walking beside each other and that the natural trajectory toward a place where spirits and bodies will meet again is home. For now, members are organized together through and on this cyber-mediated platform. Amy has designated Shelby as one who is shepherding this group of cancer patients into a specific organizational meaning. Collectively they are making real their understood meaning of death: one's bodily exit from one space and entrance into the next and the unknowable but taken for granted beliefs of existence through which these patients conceptualize death. The drawn upon sensemaking in this online environment demonstrates that members are constrained by death but liberated by a hope of a place of reunion.

At the same time, maybe not every member shares this perspective. Lynn remarks, It means a bit something different to me, I think, but fitting. She was a dear. I love you, my fellow mester-sisters I hold you both very dear. Lynn is a cancer patient and activist who regularly petitions the U.S. Congress on behalf of MBC patients, and professes to be irreligious. She directs her comment specifically to her mester-sisters are several TLR members who are fel- low activists. Her post is an example of slippage, which occurs when organizational identity is potentially disputed, but dissonance is contained and maintained nonetheless. While Lynn admits some disagreement with a heaven-bound perspective, as an active agent, she too is producing her own part of this environment. ${ }^{36} \mathrm{~A}$ pure influence of one subjectivity over another does not occur in this exchange. One member does not have absolute influence over another nor is the sensemaking of Shelby's impending death not divided or disputed; rather, it is relatable and reconciled. Enactment of this particular group's sensibility of their online environment can be summed up in relatings such as, ...I never react to you but to you-plus-me; or to be more accurate, it is I-plus-you reacting to you-plus-me. ${ }^{35}$ In this case, some member's metaphorical understanding of end of life serves to reinforce identification with each other and provides an almost substantive form of comfort in the face of loss.

\section{Discussion and Conclusions}

\section{Sensemaking: tools to cope with uncertainty}

Numerous qualitative studies of online peer-to-peer systems of support for the chronically and terminally ill have looked at the ways that patients use cyber-mediated communication as they cope with their diagnoses. Most have focused on topics ranging from information seeking and sharing, to emotional and social support, to how peer-topeer interactions may impact patient-provider relations. Few have examined the ways that chronically and terminally ill peer-to-peer online communities understand and frame their disease experience. This investigation into the online exchanges of $\mathrm{MBC}$ patients claims the use of distinct sensemaking by group members to frame their understandings of illness and disease. Specifically, members' meanings of identity, retrospective memory, and enactment of their group's environment functioned as communal frames through which uncertainty, stemming from living with a deadly disease, was understood and managed.

One of my key findings was that shared identity work was accomplished through members' narrative storytelling, words of support, and a validation of group membership seen in the welcoming of new members. Participants, as MBC patients, defined what they considered the $i t$ of the group to be their own understanding of the meaning of cancer survivorship; participants' cancer identity was constructed and shaped through online posts and responses. Among participants, there was an acceptance of the diagnosis as they readily identified with being MBC patients. Likewise, they resisted common cheerful and positive pronouncements of, This too will pass, or Kick cancer's ass; these kinds of statements were almost nonexistent between their exchanges. The lack of pink ribbon language suggests that MBC patients construct notions of survivorship identity in alternate ways. 
Another facet of identity work resulted from collaborative self-efficacy. Peers shared perceptions about drug and treatment side effects, impairment and validation of each other's illness stories acted as a reciprocal tool, shaping and protecting their sense of self. ${ }^{36}$

Connected to shared identity, retrospective memory occurred as members' reflected on what a Just say Hi moment looks like for them - not only as onlookers but as MBC patients who, themselves, could be the subject of the story. Members' attention toward the narrated event brought into relief the meaning of seeing another patient against being a mere onlooker. This attention to identify with another is spurred by the uncertainty that MBC patients face daily. Serious events such as witnessing the coding of a patient in a waiting room are framed as brutal reality, but also as events requiring a response (such as taking time to acknowledge others) because of a shared reality of suffering and death. The telling of this story and the responses to it served to frame members' patient identity as well as one's daily existence in uncertainty through the use of restrospective memory.

The final finding, enactment, was produced by members who made what they saw, to, as Weick says, see what they think.$^{23}$ Namely, TLR members' response to bad news is a discursive creation of the organizational script We are all just walking each other home. Participants, in making sense of a peer's imminent death, collectively agree upon the use of the metaphor in order to name what is happening to each of them. This agreed upon representation serves as an aspect of group and MBC identity. While some did not subscribe to religious beliefs, there was a relatability found in members enactment of or a form of running with a co-created metaphor.

I draw a number of implications from the findings in this study. First, TLR as an online, peer-to-peer, social media support community of metastatic cancer patients is one where the seeking of psychosocial support outweighs informational or instrumental support. Collaborative identity work, while not explicitly stated, was clearly a central tenant that served to normalize member's identities within the scope of discussions about diagnoses, treatments, behaviors, or outcomes. Second, members did not subscribe to a widely accepted meaning of survivor - the cheerful, victorious, and overcoming pink warrior. MBC patients in this forum eschewed optimistic images of the survivor identity; they intentionally constructed alternative ideas of survivorship. Members usually refrained from giving advice or offering hope for recovery. Not having any easy answers or the ability to fix other's dilemmas provided an environment where members produced support through what Kaufman and Whitehead describe as reciprocal empathy where the sharing of empathy produces strong supportive effects. ${ }^{37}$ A potential by-product of reciprocal empathy is a sense of normalization where peers, having shared similar stories, strengthen their disease identities by doing emotional identity work together. Finally, the meaning behind organizational/group membership was immediately understood. New members were welcomed, not with purely instrumental communication, but primarily with solidarity language. TLR members accept that they have stock in not only what the it is that defines the organization, but also the identity that is bound up with that $i t$. In this group, cancer is the it - indeed their identity; yet the disease identity that is adopted is not as straightforward as the word implies. Members rarely, if ever, invoked pink metaphors, preferring instead to adopt more blunt discussions of their experiences.

Online platforms of peer-to-peer disease support communities continue to grow in popularity as social spaces where issues of chronic and late stage disease are expressed and support is actualized. Interactions between members who are chronically or terminally ill are vital to daily coping because of the sensemaking facilitated by cyber-mediated communication. TLR's members' understandings of what I identify as shared identity, retrospective memory, and enactment of their environment enables the group's co-created knowledge to flourish, thus, as I argue, making an impact on their very experiences of the disease. Further studies should investigate how that knowledge impacts overall health outcomes, specifically for metastatic cancer patients. Additionally, in light of newer marketed therapies (such as Ibrance, Letrizole and Verzinio) and the promises of immunotherapies, MBC patients may be experience longer prognosis' and therefore contend with chronic disease differently. It behooves researchers and clinicians to study the ways that patients among themselves are understanding, meeting, and coping with these potential changes.

\section{References}

1. Czarniawska-Joerges B. A narrative approach to organization studies. Thousand Oaks, CA: Sage; 1998.

2. Weick KE. Sensemaking in organizations. Thousand Oaks, CA: Sage Publications; 1995.

3. Mullan F. Seasons of survival: reflections of a physician with cancer. N Engl J Med 1985;313:270-3.

4. Sontag S. Illness as metaphor. London: Penguin Books; 2002.

5. American Cancer Society. Breast cancer facts and figures 2005-2006. Atlanta: American Cancer Society; 2005. Available from: https://www.cancer.org/content/dam/cancerorg/research/cancer-facts-and-statistics/breast-cancer-facts-a nd-figures/breast-cancer-facts-and-figures-2005-2006.pdf

6. American Cancer Society. Breast cancer facts and figures 2017-2018. Atlanta: American Cancer Society; 2017. Available from: https://www.cancer.org/content/dam/cancerorg/research/cancer-facts-and-statistics/breast-cancer-facts-a nd-figures/breast-cancer-facts-and-figures-2017-2018.pdf

7. Kaiser K. The meaning of the survivor identity for women with breast cancer. Soc Sci Med 2008;67:79-87.

8. Helgeson VS. Survivor centrality among breast cancer survivors: implications for well-being. Psycho-Oncol 2011;20: 517-24. 
9. Ussher J, Kirsten L, Butow P, Sandoval M. What do cancer support groups provide which other supportive relationships do not? The experience of peer support groups for people with cancer. Soc Sci Med 2006;62:2565-76.

10. Preece J. Sociability and usability in online communities: determining and measuring success. Beh Inform Tech 2001;20:347-56.

11. Sillence E. Giving and receiving peer advice in an online breast cancer support group. Cyberpsych Beh Soc N 2013;16:480-5.

12. Wright KB. Communication in health-related online social support groups/communities: a review of research on predictors of participation, applications of social support theory, and health outcomes. Rev Commun Res 2016:4;65-87.

13. Sharf BF. Communicating breast cancer on-line: support and empowerment on the Internet. Women Health 1997;26:65-84.

14. Oh HJ, Lee B. The effect of computer-mediated social support in online communities on patient empowerment and doctorpatient communication. Health Commun 2012;27:30-41.

15. Sandaunet A-G. A space for suffering? communicating breast cancer in an online self-help context. Qual Health Res 2008;18:1631-41.

16. Frank AW. The wounded storyteller: body, illness, and ethics. Chicago: University of Chicago Press; 2013.

17. Bar-Lev S. "We are here to give you emotional support": performing emotions in an online HIV/AIDS support group. Qual Health Res 2008;18:509-21.

18. Rier DA. Internet social support groups as moral agents: the ethical dynamics of HIV status disclosure. Sociol Health Ill 2007;29:1043-58.

19. Coulson NS, Buchanan H, Aubeeluck A. Social support in cyberspace: a content analysis of communication within a Huntingtons disease online support group. Patient Educ Couns 2007;68:173-8.

20. Shim M, Cappella JN, Han JY. How does insightful and emotional disclosure bring potential health benefits? study based on online support groups for women with breast cancer. J Commun 2011;61:432-54.

21. Vilhauer RP. 'Them' and 'us': The experiences of women with metastatic disease in mixed-stage versus stage-specific breast cancer support groups. Psychol Health 2011;26:781-97.

22. Kingod N, Cleal B, Wahlberg A, Husted GR. Online peerto-peer communities in the daily lives of people with chronic illness. Qual Health Res 2016;27:89-99.

23. Weick KE. Enacted sensemaking in crisis situations. J Manag Stud 1988;25:305-17.

24. Schutz A, The phenomenology of the social world. New York: Northwestern University Press; 1967.

25. Landqvist M. Sense and sensibility - Online forums as epistemic arenas. Discourse Context Media 2016;13:98-105.

26. Schwandt TA. Qualitative inquiry: a dictionary of terms. Thousand Oaks, CA: Sage; 1997.

27. Elo S, Kyngas H. The qualitative content analysis process. J Adv Nurs 2008;62:107-15.

28. Bury M. Chronic illness as biographical disruption. Sociol Health Illn 1982;4:167-82.

29. Erez M, Earley PC. Culture, self-identity, and work. New York: Oxford University Press; 1993.

30. Poole MS, Angle HL, Van de Ven AH, eds. Research on the management of innovation: the Minnesota studies. New York: Harper \& Row; 1989.

31. Starbuck WH, Nystrom PC. Why the world needs organizational design. Org Industr Dev 1982;6:3-17.

32. Winokur J. Zen to go. New York: New American Library; 1989.

33. Strauss AL. The social psychology of George Herbert Mead. Chicago: University of Chicago Press; 1962.

34. Lincoln IS. Organizational theory and inquiry: the paradigm revolution. Beverly Hills: Sage Publications; 1985. pp 106-136.

35. Follett MP. Creative experience. New York: Longmans, Green; 1930.

36. Mathieson CM, Stam HJ. Renegotiating identity: cancer narratives. Sociol Health Illn 1995;17:283-306.

37. Kaufman S, Whitehead KA. Producing, ratifying, and resisting support in an online support forum. Health (London) 2018;22:223-39. 